\title{
BMJ Open The NHS Health Check in England: an evaluation of the first 4 years
}

\author{
John Robson, ${ }^{1}$ Isabel Dostal, ${ }^{1}$ Aziz Sheikh, ${ }^{2}$ Sandra Eldridge, ${ }^{1}$ \\ Vichithranie Madurasinghe, ${ }^{1}$ Chris Griffiths, ${ }^{1}$ Carol Coupland, ${ }^{3}$ Julia Hippisley-Cox ${ }^{3}$
}

To cite: Robson J, Dostal I, Sheikh A, et al. The NHS Health Check in England: an evaluation of the first 4 years. BMJ Open 2016;6: e008840. doi:10.1136/ bmjopen-2015-008840

\section{- Prepublication history} and additional material is available. To view please visit the journal (http://dx.doi.org/ 10.1136/bmjopen-2015008840)

Received 20 May 2015 Revised 1 September 2015 Accepted 28 September 2015

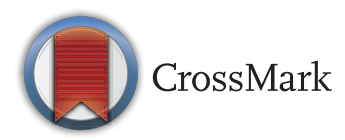

${ }^{1}$ Centre for Primary Care and Public Health, Queen Mary University of London,

London, UK

${ }^{2}$ Usher Institute of Population Health Sciences and Informatics, The University of Edinburgh, Edinburgh, UK

${ }^{3}$ School of Community Health Sciences, The University of Nottingham, Nottingham, UK

Correspondence to John Robson;

j.robson@qmul.ac.uk

\section{ABSTRACT}

Objectives: To describe implementation of a new national preventive programme to reduce cardiovascular morbidity.

Design: Observational study over 4 years (April 2009 -March 2013).

Setting: 655 general practices across England from the QResearch database.

Participants: Eligible adults aged $40-74$ years including attendees at a National Health Service (NHS) Health Check.

Intervention: NHS Health Check: routine structured cardiovascular check with support for behavioural change and in those at highest risk, treatment of risk factors and newly identified comorbidity.

Results: Of 1.68 million people eligible for an NHS Health Check, 214295 attended in the period 200912. Attendance quadrupled as the programme progressed; $5.8 \%$ in 2010 to $30.1 \%$ in 2012 . Attendance was relatively higher among older people, of whom $19.6 \%$ of those eligible at age $60-74$ years attended and $9.0 \%$ at age $40-59$ years. Attendance by population groups at higher cardiovascular disease (CVD) risk, such as the more socially disadvantaged $14.9 \%$, was higher than that of the more affluent $12.3 \%$. Among attendees 7844 new cases of hypertension (38/1000 Checks), 1934 new cases of type 2 diabetes (9/1000 Checks) and 807 new cases of chronic kidney disease (4/1000 Checks) were identified. Of the 27624 people found to be at high CVD risk (20\% or more 10-year risk) when attending an NHS Health Check, 19.3\% (5325) were newly prescribed statins and $8.8 \%$ (2438) were newly prescribed antihypertensive therapy.

Conclusions: NHS Health Check coverage was lower than expected but showed year-on-year improvement. Newly identified comorbidities were an important feature of the NHS Health Checks. Statin treatment at national scale for 1 in 5 attendees at highest CVD risk is likely to have contributed to important reductions in their CVD events.

\section{INTRODUCTION}

The English National Health Service (NHS) Health Checks programme started in 2009, aiming to reduce cardiovascular disease (CVD) risks and events. Internationally, it is

\section{Strengths and limitations of this study}

- This is the first national study describing implementation of the new National Health Service (NHS) Health Check programme 2009-2012.

- It is based on a large representative sample of 655 general practices in England with 1.68 million people aged $40-74$ years eligible for an NHS Health Check of whom 214295 attended.

- Of those eligible, $70 \%$ had ethnic group recorded and $99 \%$ socioeconomic group recorded. In attendees, recording of ethnic group and major risk factors was over $90 \%$.

- Non-attendees were younger, more likely to smoke and recording of cardiovascular risk was less complete.

- There is no information available about attendance for support for behavioural change following general practitioner (GP) referral.

the first of its kind, aiming to provide a routine structured clinical assessment and management for adults aged 40-74 years without pre-existing diabetes or CVD. The NHS Health Check includes review of CVD risks, behavioural change support and treatment of newly identified risk factors or comorbidity through integration with routine clinical provision in general practice. We describe an evaluation of the first 4 years of this national programme.

The NHS Health Check is a 5-year rolling programme which targets one-fifth of the eligible population each year, aiming to invite 3 million people at an annual cost of $£ 165$ million. ${ }^{1-3}$ The Department of Health report that 2.4 million NHS Health Checks were undertaken in the 2 years (2011-2012). ${ }^{4}$ Nationally, uptake is reported at around $50 \%$ of the eligible target population with considerable variability between provider organisations. ${ }^{4-6}$ The NHS Health Check programme is now supported by NHS England and Public Health England following major changes in the NHS in 2013 when Primary Care Trusts (PCTs) were replaced by Clinical 
Commissioning Groups (CCGs) and responsibility for commissioning the programme was transferred to the Local Authorities. ${ }^{78}$

Stratification of CVD risk for the purposes of therapeutic intervention is a key component of the NHS Health Check. Attendees receive personal advice to support behaviour change and treatment informed by CVD risk stratification. When the programme was introduced, National Institute for Health and Care Excellence (NICE) guidance and the NHS Health Check programme,${ }^{9}{ }^{10}$ recommended statin treatment at a 10-year CVD risk of $20 \%$ or more and antihypertensive treatment with blood pressure sustained at 140/ $90 \mathrm{~mm} \mathrm{Hg}$ or more. Comorbidities, including diabetes and chronic kidney disease (CKD), are identified through blood testing in the high CVD risk group with appropriate management. Familial propensity to premature ischaemic heart disease is also identified.

There is robust trial and observational evidence of benefit from statins and antihypertensives in high-risk people with and without established CVD. ${ }^{11-16}$ In people at higher CVD risk, primary prevention of CVD using multiple risk factor intervention including treatment with statins and antihypertensives has been shown to be of benefit. ${ }^{17}$ However, this has not been demonstrated in entire populations including people at lower CVD risk. For people at lower CVD risk (ie, a 10-year risk of $<10 \%$ ) for whom behavioural change is the main intervention, the most effective prevention strategy remains unclear. ${ }^{16}$

Primary prevention based on assessment of cardiovascular risk is a topic of international interest and debate. ${ }^{18-20}$ The study was commissioned by the Department of Health to provide an early view of implementation of the national programme. This study describes the results from the first 4 years of the NHS Health Check programme, the population coverage and characteristics of those who attended, their recorded GVD risks, new comorbidity and treatment. Available information on non-attendees is also reported.

\section{METHODS}

The study plan and this report conform to the STROBE recommendations for observational studies. ${ }^{21}$

QResearch is a large, nationally representative and validated primary care electronic database containing the health records of 13 million patients registered from 655 general practices using the Egton Medical Information System (EMIS) computer system for at least a year.

For the 4 years (1 April 2009 to 31 March 2013), we included in the study all eligible adults aged $40-74$ years if they had been registered for at least a year. We excluded people ineligible for an NHS Health Check, defined by the Department of Health as people with pre-existing vascular disease including hypertension, ischaemic heart disease, stroke or transient ischaemic attack, atrial fibrillation, heart failure, peripheral arterial disease, CKD, familial hypercholesterolaemia, diabetes and those already on statins. ${ }^{22}$

Read codes are used to code clinical data in primary care. NHS Health Check attendance was identified by Read codes for CVD risk assessment or NHS Health Check completed. We were unable to distinguish NHS Health Checks conducted in general practice from those conducted by a third party such as a community pharmacy. For people with an NHS Health Check, we used the date of the Check as the index date for analysis. For those without an NHS Check during the study period, we allocated an index date of 1 April in each year. The NHS Health Check is a rolling 5-year programme, and the total eligible population each year was divided by five to estimate the number eligible in any 1 year. Coverage was defined as the number of attendees in the year, as a proportion of one-fifth of the population eligible in that year.

The total eligible population and people who attended an NHS Health Check were described according to sex, age group (40-49, 50-59, 60-74) and ethnic group. Ethnic groups were combined into Office of National Statistics categories: white (British, Irish, other Caucasian); South Asian (Bangladeshi, Indian, Pakistani); black African; black Caribbean; Chinese; other Asian; other (any other recorded ethnic group including mixed ethnic groups) and ethnic group not recorded. ${ }^{23}$

Deprivation was assessed using the Townsend score based on 2001 census-derived measures of overcrowding, car ownership and education available at lower super output area. ${ }^{24}$ This was obtained by linking the individuals' postcode to lower super output area (approximately 150 households). Townsend score was accessible for $99 \%$ of patients. We grouped individuals into fifths of deprivation, with quintile 1 indicating least deprived and quintile 5 most deprived.

Information on smoking status, alcohol intake and risk factor recording was described for attendees and nonattendees. This included the latest information recorded up to and including the date of the NHS Health Check for attendees or the index date for non-attendees. Family history of ischaemic heart disease was coded as positive if a first-degree relative had angina or a heart attack under age 60 years. Information on alcohol consumption was categorised by units consumed per day (non-drinker, $<1,1-2,3-6,7-9,>9+$ ) although it was not nationally part of the NHS Health Check during the study period. Information was also extracted on whether a recorded CVD risk score was estimated by either Framingham or QRisk2 using the same time frame as specified above. Where a score was recorded we used it to identify people at high CVD risk, defined as a 10-year CVD risk of $20 \%$ or more.

In people who attended a Health Check, information was extracted on medications, new morbidities, risk factor recording and referrals on the date of the check or in the following 12 months. The equivalent 
information was extracted for non-attendees for the 12 months from their index date. New medication was defined as at least two statin or antihypertensive prescriptions within 12 months. New comorbidities, including diagnosed hypertension, CKD categories 3-5 and diabetes, were included if newly recorded within 12 months of an NHS Health Check. Abnormal measurements were not classified as a diagnosis unless a diagnostic code was recorded. For example, a raised blood pressure was not classified as hypertension unless the diagnostic code for hypertension was recorded.

The data were analysed using STATA V.13 (STATA Corps). We calculated proportions of people who attended by categories of age, sex and ethnic group. We calculated proportions according to levels of smoking status, alcohol intake and risk factors in those who did and did not attend an NHS Health check. We also described CVD risk levels and outcomes in attendees following the NHS Health Check. We did not carry out statistical comparisons of NHS Health Check attendees with non-attendees, as data were incomplete in the latter.

\section{RESULTS}

Over the 4-year study period (1 April 2009-31 March 2013) 1679024 people were eligible for an NHS Health Check. Of these, $12.8 \%$ (214 295) patients were recorded as having had an NHS Health Check (see figure 1).

One-fifth of the eligible population was considered available for attendance each year.

Table 1 shows coverage by financial year. In 2009/ 2010, there were a total 1430174 people eligible of whom 286035 (one-fifth) were considered eligible in the year, and of these, 5.8\% (16 613/286 035) attended an NHS Health Check. In 2010/11, $14.6 \%$ attended; in 2011/12, 24.4\% attended; and in 2012/13, 30.1\% attended.

Figure 1 Flow-chart showing inclusion and exclusion of people eligible for an NHS Health Check and attendance. CKD, chronic kidney disease; CVD, cardiovascular disease; NHS, National Health Service.
Table 1 Coverage of National Health Service (NHS) Health Check programme in each year

\begin{tabular}{llll}
\hline & $\begin{array}{l}\text { Patients } \\
\text { with health } \\
\text { check in } \\
\text { financial }\end{array}$ & $\begin{array}{l}\text { 20\% of the } \\
\text { eligible } \\
\text { population } \\
\text { on 1 April }\end{array}$ & $\begin{array}{l}\text { Percentage of } \\
\text { coverage } \\
\text { attendance/ } \\
\text { one-fifth of } \\
\text { eligible } \\
\text { population }\end{array}$ \\
$\begin{array}{l}\text { Financial } \\
\text { years }\end{array}$ & year & 286035 & 5.8 \\
\hline $2009 / 2010$ & 16613 & 286383 & 14.6 \\
$2010 / 2011$ & 41832 & 28636 & 24.4 \\
$2011 / 2012$ & 69978 & 286669 & 30.1 \\
$2012 / 2013$ & 86042 & 285784 &
\end{tabular}

Table 2 shows NHS Health Check coverage for different eligible population subgroups during the entire 4 -year study period. Of those eligible aged $60-74$ years, $19.6 \%$ attended, and at age $40-59$ years, $9.0 \%$ attended. In the most deprived quintile, $14.9 \%$ attended, and in the least deprived quintile, $12.3 \%$ attended.

Seventy per cent (1 174646/1679 024) of the eligible population had ethnic group recorded. There was low attendance, $2.1 \%$ among the $30 \%$ of the eligible population without ethnicity recorded. Among those with ethnic group recorded, coverage was highest among South Asians (Indian, Pakistani, Bangladeshi, other Asian) of whom $19.2 \%$ of the eligible population attended, and black Caribbeans $19.6 \%$, and lowest in black Africans $15.7 \%$ and Chinese $15.3 \%$. In white people, $17.4 \%$ attended compared with $16.9 \%$ in all other recorded ethnic groups.

Table 3 shows information on risk factor recording and CVD risk score recording among attendees and non-attendees prior to or at the NHS Health Check or the equivalent index date for non-attendees. Smoking status was recorded in $99.9 \%$ of attendees and $94.5 \%$ of 
Table 2 Characteristics of people aged 40-74 years eligible for a National Health Service (NHS) Health Check between April 2009 and March 2013 and those who attended

\begin{tabular}{|c|c|c|c|}
\hline & Total eligible people & $\begin{array}{l}\text { NHS Health } \\
\text { Check attendees }\end{array}$ & $\begin{array}{l}\text { Percentage of total eligible } \\
\text { population with } \\
\text { NHS Health Check }\end{array}$ \\
\hline Total & 1679024 & 214295 & 12.8 \\
\hline Female & 846797 & 111740 & 13.2 \\
\hline Male & 832227 & 102555 & 12.3 \\
\hline \multicolumn{4}{|l|}{ Age band (years) } \\
\hline $40-49$ & 806199 & 72903 & 9.0 \\
\hline $50-59$ & 499725 & 68428 & 13.7 \\
\hline $60-74$ & 373100 & 72964 & 19.6 \\
\hline \multicolumn{4}{|c|}{ Townsend quintile of deprivation } \\
\hline 1 (most affluent) & 336174 & 41423 & 12.3 \\
\hline 2 & 334996 & 40342 & 12.0 \\
\hline 3 & 335706 & 40897 & 12.2 \\
\hline 4 & 335302 & 41557 & 12.4 \\
\hline 5 (most deprived) & 334652 & 49974 & 14.9 \\
\hline Townsend not recorded & 2194 & 102 & 4.7 \\
\hline \multicolumn{4}{|l|}{ Ethnicity } \\
\hline White & 1065171 & 185082 & 17.4 \\
\hline Indian & 16842 & 2987 & 17.7 \\
\hline Pakistani & 8472 & 1362 & 16.1 \\
\hline Bangladeshi & 4925 & 1460 & 29.6 \\
\hline Other Asian & 13471 & 1966 & 14.6 \\
\hline Caribbean & 12908 & 2531 & 19.6 \\
\hline Black African & 19899 & 3128 & 15.7 \\
\hline Chinese & 6913 & 1059 & 15.3 \\
\hline Other & 26045 & 4059 & 15.6 \\
\hline Not recorded & 504378 & 10661 & 2.1 \\
\hline
\end{tabular}

non-attendees. Non-attendees were more likely to be smokers. In total, $17.7 \%$ of attendees were smokers, and $22.4 \%$ of non-attendees were smokers. Alcohol consumption was recorded for $95.9 \%$ of attendees and $80.3 \%$ for non-attendees. Among those in whom alcohol consumption was recorded, heavy drinking ( $>9$ units/ day) was reported by $2.5 \%$ of attendees and $2.2 \%$ of non-attendees.

CVD risk using QRisk2 was assessed in $80.0 \%$ (171 441/214 295) of attendees and in 29.0\% (424 523/ 1464 729) of non-attendees and versions of Framingham were used in $15.5 \%$ (33 260/214 295) of attendees and $5.2 \%(76051 / 1464729)$ of non-attendees.

Of those attendees with QRisk2 scores recorded, $14.5 \%(24869 / 171441)$ were at high CVD risk (10-year risk of $20 \%$ or more), and $20.7 \%$ (4733/33 260) of those with Framingham scores recorded were at high CVD risk. In total, 12.9\% (27 624/214 295) of all attendees were recorded at high CVD risk $(20 \%$ or more 10-year risk) using either QRisk2 or Framingham. Among non-attendees with QRisk2 recorded, 6.6\% (27 902/424 523) were at high CVD risk and $8.6 \%$ of non-attendees were at high CVD risk $(6547 / 76$ 051) using Framingham.

Of those attendees with a QRisk2 score recorded, $46.6 \%(79960 / 171441)$ had a CVD risk of $10 \%$ or more. In the non-attendees with a recorded QRisk2 score, $27.0 \%(114564 / 424523)$ were at $10 \%$ or more GVD risk.

\section{NEW COMORBIDITY}

Table 4 records new comorbidity identified at or in the 12 months after the NHS Health Check from 2009 to 2012. This included 7844 new cases of hypertension (1 case per 27 NHS Health Checks), 1934 new cases of diabetes ( 1 new case for every 110 Checks) and 807 new cases of CKD (1 new case in every 265 Checks).

Recording of new comorbid conditions in the year after an NHS Check was higher in people attending NHS Health Checks than recording in the year after the index date in non-attendees. However, in non-attendees, missing data are a major issue which precludes simple direct comparison between attendees and nonattendees. Risk factors requiring further follow-up were recorded in more than one in five attendees. Raised blood pressure ( $\geq 140 / 90 \mathrm{~mm} \mathrm{Hg}$; but not recorded as a diagnosis of hypertension) was identified in $18.5 \%$ (26 126/140 995), obesity (body mass index (BMI) $\left.\geq 30 \mathrm{~kg} / \mathrm{m}^{2}\right)$ in $15.0 \%(32133 / 151480)$ and raised fasting blood sugar (but not recorded as a diagnosis of diabetes) in 2.7\% (954/35 801).

In total, $33.9 \%$ of heavy and very heavy alcohol drinkers $(1823 / 5376)$ were referred for further advice, and 
Table 3 Characteristics of eligible people who did and did not attend for a NHS Health Check recorded prior to or on the date of the NHS Health Check or relevant index date

\begin{tabular}{|c|c|c|}
\hline & $\begin{array}{l}\text { NHS Health Check } \\
\mathrm{N}(\%)\end{array}$ & $\begin{array}{l}\text { No NHS Health Check } \\
\text { N (\%) }\end{array}$ \\
\hline Total & 214295 & 1464729 \\
\hline Smoking status recorded & 214020 (99.9) & 1384707 (94.5) \\
\hline Non-smoker & $117968(55.1)$ & $768276(55.5)$ \\
\hline Ex-smoker & $58244(27.2)$ & $306397(22.1)$ \\
\hline Light smoker (1-9/day) & $19589(9.2)$ & $167592(12.1)$ \\
\hline Moderate smoker (10-19/day) & $11052(5.2)$ & $83585(6.0)$ \\
\hline Heavy smoker (20+/day) & 7167 (3.3) & 58857 (4.3) \\
\hline \multicolumn{3}{|l|}{ Alcohol intake } \\
\hline Alcohol status recorded & 205506 (95.9) & $1175900(80.3)$ \\
\hline Non-drinker & $53485(26.0)$ & $292289(24.9)$ \\
\hline Trivial $<1$ units/day & $66780(32.5)$ & $421139(35.8)$ \\
\hline Light $1-2$ units/day & $37398(18.2)$ & $205572(17.5)$ \\
\hline Moderate 3-6 units/day & 42467 (20.7) & $227987(19.4)$ \\
\hline Heavy $7-9$ units/day & 3235 (1.6) & $17169(1.5)$ \\
\hline Very heavy $>9$ units/day & $1866(0.9)$ & $8842(0.8)$ \\
\hline Drinker-amount not recorded & $275(0.1)$ & $2902(0.2)$ \\
\hline \multicolumn{3}{|l|}{ Risk factor recording } \\
\hline Body mass index recorded & $210062(98.0)$ & $1176819(80.3)$ \\
\hline Systolic blood pressure recorded & 213690 (99.7) & $1316926(89.9)$ \\
\hline Cholesterol recorded & 195994 (91.5) & $633548(43.3)$ \\
\hline Cholesterol/HDL recorded & $174345(81.4)$ & 433594 (29.6) \\
\hline Positive family history CHD & 46466 (21.7) & $156604(10.7)$ \\
\hline Mean body mass index (SD) & $27.14 .5)$ & $26.4(4.6)$ \\
\hline Mean cholesterol (SD) & $5.5(1.0)$ & $5.4(1.0)$ \\
\hline Mean cholesterol/HDL (SD) & $4(1.3)$ & $4(1.2)$ \\
\hline Mean SBP (SD) & $130.8(16.9)$ & $128.4(15.6)$ \\
\hline Mean DBP (SD) & $79.4(10.0)$ & $78.6(9.4)$ \\
\hline QRisk2 recorded & $171441(80.0)$ & $424523(29.0)$ \\
\hline QRisk2 not recorded & $42854(20.0)$ & $1040206(71.0)$ \\
\hline \multicolumn{3}{|l|}{ QRisk2 score } \\
\hline$<5 \%$ & 47794 (22.3) & 195253 (13.3) \\
\hline $5-9.99 \%$ & $43687(20.4)$ & $114706(7.8)$ \\
\hline $10-14.99 \%$ & 32452 (15.1) & $55306(3.8)$ \\
\hline $15-19.99 \%$ & 22639 (10.6) & $31356(2.1)$ \\
\hline $20+\%$ & 24869 (11.6) & $27902(1.9)$ \\
\hline Framingham score recorded & 33260 (15.5) & 76051 (5.2) \\
\hline Not recorded & $181035(84.5)$ & $1388679(94.8)$ \\
\hline \multicolumn{3}{|l|}{ Framingham score } \\
\hline$<5 \%$ & $7152(3.3)$ & $20532(1.4)$ \\
\hline $5-9.99 \%$ & $10196(4.8)$ & $25898(1.8)$ \\
\hline $10-14.99 \%$ & $6896(3.2)$ & $15286(1.0)$ \\
\hline $15-19.99 \%$ & $4283(2.0)$ & $7787(0.5)$ \\
\hline $20+\%$ & $4733(2.2)$ & $6547(0.4)$ \\
\hline 20+ QRisk2 or Framingham & $27624(12.9)$ & $32481(2.2)$ \\
\hline
\end{tabular}

in people who were obese (BMI $\left.\geq 30 \mathrm{~kg} / \mathrm{m}^{2}\right), 38.7 \%$ (12 430/32 133) received advice on weight reduction and $41.4 \%(13309 / 32133)$ on physical activity. In total, $6.8 \%(2571 / 37808)$ of smokers were referred to dedicated smoking cessation services.

New recurrent prescriptions for statins (two or more prescriptions within 12 months) were provided for $5.1 \%$ (10 900) of attendees and new recurrent prescriptions for antihypertensives for $3.9 \%$ (8497) of attendees.
Equivalently 1 in 20 attendances resulted in recurrent statin prescriptions, and 1 in 25 attendances resulted in recurrent antihypertensive prescriptions.

\section{ATTENDEES AT HIGH CVD RISK}

Table 5 shows the characteristics of those at high CVD risk ( $\geq 20 \%$ risk) who attended for an NHS Health Check. In total, 12.9\% (27 624/214 295) attendees were 
Table 4 Outcomes for people who did and did not have an NHS Health Check (number, \%) recorded at NHS Health Check, relevant index date or in 12 months following these dates

\begin{tabular}{|c|c|c|}
\hline & $\begin{array}{l}\text { NHS Health Check } \\
\mathrm{N}(\%)\end{array}$ & $\begin{array}{l}\text { No NHS Health Check } \\
\text { N (\%) }\end{array}$ \\
\hline Total patients & 214295 & 1464729 \\
\hline \multicolumn{3}{|l|}{ New diagnoses } \\
\hline Chronic kidney disease (eGFR $<60 \mathrm{~mL} / \mathrm{min} /$ ) & $807(0.4)$ & $2310(0.2)$ \\
\hline Type 2 diabetes & $1934(0.9)$ & $5647(0.4)$ \\
\hline Hypertension & $7844(3.7)$ & $16184(1.1)$ \\
\hline \multicolumn{3}{|l|}{ Risk factor recording } \\
\hline Body mass index recorded & $151480(70.7)$ & $144756(9.9)$ \\
\hline Positive family history of premature CHD recorded & $14760(6.9)$ & $4720(0.3)$ \\
\hline Blood pressure recorded & $140995(65.8)$ & $242928(16.6)$ \\
\hline eGFR recorded & $59021(27.5)$ & $160843(11.0)$ \\
\hline Fasting glucose & $35801(16.7)$ & $78934(5.4)$ \\
\hline Random glucose & $64439(30.1)$ & $102568(7.0)$ \\
\hline Total cholesterol recorded & $123342(57.6)$ & $137207(9.4)$ \\
\hline Cholesterol/HDL ratio recorded & $118930(55.5)$ & $115011(7.9)$ \\
\hline Smoking status recorded & $188282(87.9)$ & 410301 (28.0) \\
\hline \multicolumn{3}{|l|}{ Risk factors identified (as \% recorded) } \\
\hline Fasting glucose $\geq 7 \mathrm{mmol} / \mathrm{L}$ & $954(2.7)$ & $2983(3.7)$ \\
\hline Random glucose $\geq 11 \mathrm{mmol} / \mathrm{L}$ & $421(0.6)$ & $1291(1.3)$ \\
\hline Raised BP: SBP $\geq 140 \mathrm{mmHg}$ or DBP $\geq 90 \mathrm{mmHg}$ & $26126(18.5)$ & $52236(21.5)$ \\
\hline Obesity $\mathrm{BMI} \geq 30 \mathrm{~kg} / \mathrm{m}^{2}$ & $32133(21.2)$ & $39774(27.5)$ \\
\hline \multicolumn{3}{|l|}{ New referrals (as \% recorded) } \\
\hline Current smokers referred to smoking cessation clinic & $2571(6.8)$ & 9944 (3.2) \\
\hline Weight referrals: $\mathrm{BMI} \geq 30 \mathrm{~kg} / \mathrm{m}^{2}$ & $12430(38.7)$ & 4441 (11.2) \\
\hline Exercise referrals: $\mathrm{BMI} \geq 30 \mathrm{~kg} / \mathrm{m}^{2}$ & $13309(41.4)$ & $4082(10.3)$ \\
\hline Alcohol referrals: $>6$ units/day & $1823(33.9)$ & $1459(5.1)$ \\
\hline \multicolumn{3}{|l|}{ New medication } \\
\hline $2+$ prescriptions for statins & $10900(5.1)$ & $15086(1.0)$ \\
\hline $2+$ prescriptions for antihypertensives & $8457(3.9)$ & $26178(1.8)$ \\
\hline
\end{tabular}

recorded at high CVD risk. As expected, those at high CVD risk were older, with $81.0 \%$ of high-risk attendees in the 60-74-year age group compared with $34.0 \%$ of all attendees. Men comprised $78.3 \%$ in the high-risk group and $47.9 \%$ among all attendees.

As expected, all other risk factors were more prevalent in those at high CVD risk. Of the high CVD risk attendees, 23.2\% (4222/18 203) were obese and 28\% (7743/ 27611 ) were smokers. Blood pressure was $\geq 140 /$ $90 \mathrm{~mm} \mathrm{Hg}$ in $30.0 \%(4772 / 15905)$ at high CVD risk compared with $18.5 \%$ (26 126/140 995) in all attendees. Of those NHS Health Check attendees at high CVD risk, $19.3 \%(5325 / 27624)$ were prescribed recurrent statins and $8.8 \%(2438 / 27624)$ were prescribed recurrent antihypertensive therapy.

\section{REFERRALS TO BEHAVIOURAL SUPPORT}

Online supplementary appendix table shows referrals for behavioural interventions in people at high CVD risk. Using data from tables 3 and 4, it can be shown that most referrals took place in people at lower CVD risk $(<20 \%$ over 10 years $)$. Of those people with behaviourally mediated risk factors recorded-smoking, obesity and high alcohol consumption-who were referred for further support during an NHS Health Check, 80.0\% were not in the high CVD risk group. Of the smoking cessation referrals made in smokers, $17.1 \%(439 / 2571)$ were in smokers at high CVD risk and $82.9 \%$ were in people at lower risk. Of the dietary referrals made in people with BMI $\geq 30 \mathrm{~kg} / \mathrm{m}^{2}, 13.6 \%(1691 / 12430)$ were in people at high CVD risk and $86.4 \%$ were in people at lower risk. Similarly of the referrals for physical activity, $13.4 \%(1780 / 13$ 309) were in people at high CVD risk and $86.6 \%$ were in people at lower risk. Of the total referrals for alcohol reduction support for heavy or very heavy drinkers, $16.5 \%(300 / 1823)$ were in people at high CVD risk and $83.5 \%$ were in people at lower risk.

In total, $5.7 \%(1139 / 7743)$ of smokers at high CVD risk were referred to accredited level 2 or 3 smoking cessation services. In people at high CVD risk with BMI $\geq 30 \mathrm{~kg} / \mathrm{m}^{2}, 40.0 \%(1691 / 4222)$ were referred to dietary and $42.2 \%(1780 / 4222)$ to physical activity support services, and $33.1 \%(300 / 905)$ of those at high CVD risk recorded as drinking seven or more units of alcohol per day were referred to alcohol reduction services. 
Table 5 Characteristics of people at high CVD risk who attended an NHS Health Check 1 April 2009 to 31 March 2013 recorded at or prior to the date of the NHS Health Check

\begin{tabular}{|c|c|}
\hline & $\begin{array}{l}\text { NHS Health Check risk } \\
\geq 20 \% \\
\text { N (\%) }\end{array}$ \\
\hline Total patients all CVD risks & 214295 \\
\hline Total with CVD risk $\geq 20 \%$ & 27624 \\
\hline Females & $5992(21.7)$ \\
\hline Males & $21632(78.3)$ \\
\hline \multicolumn{2}{|l|}{ Age band (years) } \\
\hline $40-49$ & $778(2.8)$ \\
\hline $50-59$ & 4475 (16.2) \\
\hline $60-74$ & 22371 (81.0) \\
\hline \multicolumn{2}{|l|}{ Townsend quintile } \\
\hline 1 (most affluent) & $5135(18.6)$ \\
\hline 2 & $5356(19.4)$ \\
\hline 3 & $5301(19.2)$ \\
\hline 4 & $5284(19.1)$ \\
\hline 5 (most deprived) & 6539 (23.7) \\
\hline \multicolumn{2}{|l|}{ Ethnicity } \\
\hline Ethnicity recorded & 26392 (95.5) \\
\hline White & 25037 (90.6) \\
\hline Indian & $376(1.4)$ \\
\hline Pakistani & $264(1.0)$ \\
\hline Bangladeshi & $276(1.0)$ \\
\hline Other Asian & $135(0.5)$ \\
\hline Caribbean & $89(0.3)$ \\
\hline Black African & $27(0.1)$ \\
\hline Chinese & $17(0.1)$ \\
\hline Other & $171(0.6)$ \\
\hline Not recorded & $1232(4.5)$ \\
\hline Smoking status recorded & $27611(100.0)$ \\
\hline Non-smoker & $10517(38.1)$ \\
\hline Ex-smoker & 9351 (33.9) \\
\hline Light smoker (1-9/day) & 4024 (14.6) \\
\hline $\begin{array}{l}\text { Moderate smoker (10-19/ } \\
\text { day) }\end{array}$ & $2199(8.0)$ \\
\hline Heavy smoker (20+/day) & $1520(5.5)$ \\
\hline \multicolumn{2}{|c|}{ Alcohol intake prior to or at NHS Health Check } \\
\hline Alcohol status recorded & 26765 (96.9) \\
\hline Non-drinker & $6897(25.0)$ \\
\hline Trivial $<1$ units/day & $7919(28.7)$ \\
\hline Light $1-2$ units/day & $4684(17.0)$ \\
\hline Moderate 3-6 units/day & $6322(22.9)$ \\
\hline Heavy 7-9 units/day & $601(2.2)$ \\
\hline Very heavy $>9$ units/day & $304(1.1)$ \\
\hline $\begin{array}{l}\text { Drinker: amount not } \\
\text { recorded }\end{array}$ & $38(0.1)$ \\
\hline \multicolumn{2}{|c|}{ Risk factor recording prior to or at NHS Health Check } \\
\hline Body mass index recorded & $27243(98.6)$ \\
\hline $\begin{array}{l}\text { Systolic blood pressure } \\
\text { recorded }\end{array}$ & $27600(99.9)$ \\
\hline Cholesterol recorded & $26241(95.0)$ \\
\hline $\begin{array}{l}\text { Positive family history of } \\
\text { premature CHD }\end{array}$ & $9503(34.4)$ \\
\hline Mean body mass index (SD) & $27.6(4.2)$ \\
\hline
\end{tabular}

These proportions of people at high CVD risk referred to smoking cessation, dietary, physical activity and alcohol services were very similar to the proportions of all attendees (tables 3 and 4 ) who were referred, of whom $6.8 \%$ $(2571 / 37808)$ of smokers were referred to smoking cessation, $38.7 \%$ (12 430/32 133) of BMI $\geq 30$ to dietary and $41.4 \%(13309 / 32133)$ of $\mathrm{BMI} \geq 30$ to physical activity support services, and $35.7 \%(1823 / 5101)$ of heavy drinkers were referred to alcohol reduction services.

\section{DISCUSSION}

This is the first study to describe national results from the NHS Health Check programme. In 2012, the most recent year reported, $30.1 \%$ of the eligible population attended. Attendance was more likely over age 65 years $19.6 \%$ than in those under 65 years $(9.0 \%)$ and among those people in the most deprived quintile $(14.9 \%)$ versus the least deprived (12.3\%). In total, $12.9 \%$ of all attendees were recorded at high CVD risk (20\% or more 10 -year risk). There were differences in attendance between ethnic groups, though these could be due to missing data. Attendance in white people was similar to those with non-white ethnic group recorded.

New comorbidity identified in the 4-year period included 7844 new cases of hypertension (1 case per 27 NHS Health Checks), 1934 new cases of diabetes (1 new case for every 110 Checks) and 807 new cases of CKD (1 new case in every 265 Checks). Records of risk factors were more incomplete in non-attendees who had a different CVD risk profile to those who attended. Non-attendees were younger and more likely to be smokers than attendees. Because of differences in the characteristics and recording of risk factors between attendees and non-attendees, we have not made formal statistical comparisons of new morbidity between these groups.

In addition to those people with new comorbidities diagnosed, risk factors such as raised blood pressure, raised blood sugar and obesity requiring further follow-up were recorded in more than one in five of attendees. Most referrals for behavioural interventions took place in people at lower CVD risk. Of those people with behaviourally mediated risk factors recordedsmoking, obesity and alcohol consumption-who were referred for further support during an NHS Health Check, $80 \%$ were not in the high CVD risk group. The proportion of people in the high CVD risk group referred because of risk factors was similar to the proportion referred among all attendees.

One in 20 attendances resulted in recurrent statin prescription and 1 in 25 attendances resulted in recurrent antihypertensive prescription. Of those NHS Health Check attendees at high CVD risk, $19.3 \%$ were prescribed recurrent statins and $8.8 \%$ were prescribed recurrent antihypertensive therapy. 
This is a large and nationally representative study including records of social deprivation and ethnicity. Coverage of $30 \%$ was lower than expected, though attendance quadrupled during the course of the study reflecting the early phase of implementation. There was no evidence that older people, or those in the more deprived quintile were less likely to attend than other groups. South Asians who have higher CVD risks were more likely to attend than other ethnic groups. Though missing data might account for this, similar differences have been found in other studies. ${ }^{25}$ Currently attendance at NHS Health Checks is reported as uptake in response to invitation rather than coverage, defined as attendance as a proportion of the eligible population as reported in this paper. ${ }^{4}$

The NHS Health Check programme is an example of systematic implementation at national scale, of a stratified approach to advice and effective treatment in people at increased CVD risk. QRisk2 was used in $80 \%$ of NHS Checks reported in this study and is fully integrated with the EMIS computer systems used by general practitioners in this study and has since been recommended as the risk algorithm of choice in the 2014 NICE guidance $;^{26}$ an example of successful translation of clinical decision support at scale. ${ }^{27} 28$ This algorithm is fully integrated with the electronic primary care record, a key enabling factor for implementation. ${ }^{29}$

\section{LIMITATIONS OF THE STUDY}

There is no nationally available data on the extent of provision of the NHS Health Check outside of general practices. However, these were likely to represent less than $10 \%$ of NHS Health Checks undertaken, as in most PCTs the NHS Health Check was conducted almost entirely in general practice with limited use of community programmes targeting hard-to-reach groups or, with the exception of a few areas, community pharmacies. Completeness of NHS Health Checks was not ascertained, but taking measurement of cholesterol recording of $91.5 \%$ as a proxy measure, risk ascertainment was generally well conducted.

Of the people referred with behavioural risk factors, $80 \%$ were at lower CVD risk, which indicates the wide distribution of risk factors and the potential for behaviour change if programmes can be shown to be effective. Like other recent studies, referral rates were generally low, ${ }^{30}$ and little is known about attendance at, or quality of behavioural programmes even for those at higher CVD risk. Lack of consistent coding of referrals in earlier years of the NHS Health Check programme and the availability of local services for behavioural change may have contributed to low referral rates. The impact of the NHS Health Check programme on people at lower risk is unknown and further research is required. ${ }^{31}$

The study is descriptive and was not designed to determine variability between practices or CCGs. The study has not assessed changes in risk factors or cardiovascular events between comparable groups. These comparisons are difficult in a non-randomised study, especially if one group is at higher risk than the other or information is incomplete. For these reasons, we have not directly compared attendees with non-attendees. Communication of results and patient behaviours following NHS Health Checks remains an under-researched area. ${ }^{32-34}$

\section{IMPLICATIONS FOR PRACTICE}

A number of local studies suggest that the programme has been better implemented in some areas with coverage of $80 \%$ and statin prescription of up to $50 \%$ in highrisk individuals in some CCGs. ${ }^{25}{ }^{35}$ Nationally, uptake in 2011-2012 was reported as 45\%, with high levels of variability and better uptake in more deprived areas. ${ }^{6} 5$ There is limited evidence of effectiveness ${ }^{35}$ or comorbidities identified ${ }^{36}$ and statin uptake in those at high risk was reported to be between $20 \%$ and $50 \%,{ }^{5} 25$ which accords with national surveys of $32 \% .{ }^{37}$

Despite a statin treatment rate of only $19 \%$ in high-risk attendees in this study, this is likely to have had an important impact on CVD events in those treated. Assuming that 1.2 million people attended a NHS Check each year in the 5 years since 2010, of whom $10 \%$ (120 000) were at high CVD risk averaging $2.5 \%$ per year, and $19.3 \%$ (23 160) of these people were treated with statins over this period and 8.8\% (10 560) were treated with antihypertensives; if each treatment reduces cardiovascular risk by $20 \%$, it is estimated that 2529 people would avoid a major CVD event over a 5-year period. ${ }^{11}{ }^{12}$ Higher uptake in recent years and additional treatment in people at both high CVD risk and at lower CVD risk make this a conservative estimate and behavioural change will have further impact. ${ }^{37}$ These estimates assume that patients who are prescribed medications take them for a 5-year period and that the impact on outcomes is similar to that described in the trial meta-analyses cited.

The NHS Health Check programme has had a difficult birth. The efficacy of the programme has been challenged ${ }^{38-41}$ based largely on a review of 16 trials of health checks, of which 12 trials were undertaken more than 20 years ago before $1994,{ }^{42-52}$ the year in which the landmark $4 \mathrm{~S}$ trial established statin effectiveness. ${ }^{53}$ This means that 12 out of 16 of the reported studies were conducted before statins or modern antihypertensive drugs were used. Of the trials since 1994, only one ${ }^{52}$ specifically recommended drug treatment for CVD risk, the other three offering advice but no drug treatment. ${ }^{54-56}$ The results of the Inter99 study of intensive lifestyle counselling published subsequent to this review $^{57}$ showed no reduction in CVD. Despite high-quality review of trial evidence showing net benefit, ${ }^{11}$ statins have continued to received considerable adverse publicity $^{58}{ }^{59}$ which has been refuted. ${ }^{60}$

There have also been organisational factors that have impacted on implementation of the programme. Major 
organisational change in the NHS in the context of financial austerity ${ }^{61}{ }^{62}$ led to one-third of staff leaving many PCTs in the transition to CCGs in April $2013^{63}$ and commissioning responsibility for NHS Checks passed to Local Authorities. It is perhaps not surprising that in 2013, 27/151 PCTs nationally offered NHS Health Checks to fewer than $10 \%$ of eligible individuals and uptake could be substantially improved. ${ }^{64}$ The most efficient means to deliver this programme including delivery through pharmacies and likely economic impact, remain subjects for further research and debate. A range of infrastructural issues and new research are currently being addressed by Public Health England. ${ }^{65} 66$

This study indicates limited though improving success in the early years of a major new national preventive programme. Coverage of $30 \%$ and statin treatment of $19 \%$ of attendees at high CVD risk leave considerable room for improvement. New comorbidity and abnormal risk factors were frequently identified in people who attended an NHS Health Check. The majority of referrals for abnormal risk factors were among people at lower CVD risk. This modest start to a major new programme at scale is likely to have made an important impact on CVD events in people who have been treated with statins and antihypertensives or who improved adverse risk factors.

Acknowledgements The authors thank EMIS practices, EMIS and the University of Nottingham for the use of QResearch for this study.

Contributors JR initiated the study and has contributed to its design and implementation. JH-C contributed to the research question, design, data extraction, data analysis, interpretation and comments on the manuscript. CC advised on the statistical analysis and interpretation. ID conducted a preliminary investigation in one CCG that informed the study design, preparation of the code sets and study specification. SE and VM supported the statistical analysis and interpretation and all authors including CG and AS contributed to the study design and all authors contributed to the manuscript. The views expressed in this publication are those of the authors and do not necessarily represent those of those of the Department of Health or institutions that fund or support the authors

Funding This study is independent research commissioned and funded by the Department of Health Policy Research Programme (as the NHS Health Check Programme evaluation 009/0052). AS is supported by a Harkness Fellowship in Health Care Policy and Practice from The Commonwealth Fund. All other authors are funded by their host organisation.

Competing interests All authors have completed the Unified Competing Interests form at http://www.icmje.org/coi disclosure.pdf (available on request from the corresponding author) and declare that (1) JR, JH-C, CC and AS are authors of QRisk, one of the CVD Scores widely used in the NHS Health Check programme. JR was Chair of a National Institute for Health and Care Excellence Guideline that recommended systematic use of CVD scores in 2008. JH-C is also the director of ClinRisk Ltd which produces open and closed source software to ensure the reliable and updatable implementation of clinical risk algorithms (including QRISK) within clinical computer systems to help improve patient care. CC is an associate professor of Medical Statistics at the University of Nottingham and a consultant statistician for ClinRisk Ltd. The NIHR grant which funded this project provided funds to SE, JR, ID, JH-C and CC for their contribution to the study.

Ethics approval The Trent Research Ethics committee has approved use of the QResearch database for anonymised use of primary care data (http:// www.qresearch.org).
Provenance and peer review Not commissioned; externally peer reviewed.

Data sharing statement No additional data are available.

Open Access This is an Open Access article distributed in accordance with the terms of the Creative Commons Attribution (CC BY 4.0) license, which permits others to distribute, remix, adapt and build upon this work, for commercial use, provided the original work is properly cited. See: http:// creativecommons.org/licenses/by/4.0/

\section{REFERENCES}

1. Public Health England. NHS Health Check programme standards. NHS England, 2014. http://www.healthcheck.nhs.uk/commissioners and_healthcare_professionals/national_guidance/ (accessed $12 \mathrm{Mar}$ 2015).

2. Kerr M. NHS Health Check costs, benefits and savings. Department of Health, 2012. http://www.nhshealthcheck.nhs.uk/default.aspx? alD=18 (accessed 12 Mar 2015).

3. Public Health England. NHS Health Check programme best practice guidance, 2013. http://www.healthcheck.nhs.uk/commissioners and healthcare professionals/national guidance/ (accessed $12 \mathrm{Mar}$ 2015).

4. Department of Health. NHS Health Checks 2011-13, 2013. http:// www.england.nhs.uk/statistics/integrated-performance-measuresmonitoring/nhs-health-checks-data/ (accessed 12 Mar 2015).

5. Nicholas JM, Burgess $\mathrm{C}$, Dodhia $\mathrm{H}$, et al. Variations in the organization and delivery of the 'NHS health check' in primary care. $J$ Public Health (Oxf) 2013;35:85-91.

6. Artac M, Dalton AR, Babu $\mathrm{H}$, et al. Primary care and population factors associated with NHS Health Check coverage: a national cross-sectional study. J Public Health (Oxf) 2013;35:431-9.

7. Department of Health. Living well for longer: a call to action on avoiding premature mortality. London, 2013.

8. Department of Health. Improving outcomes for people with or at risk of cardiovascular disease. London, 2013. https://www.gov.uk/ government/publications/cardiovascular-disease-outcomes-strategyimproving-outcomes-for-people-with-or-at-risk-ofcardiovascular-disease (accessed 12 Mar 2015)

9. Department of Health. Putting prevention first: NHS Health check: vascular risk assessment and management. Best practice guidance. London, 2009. http://www.healthcheck.nhs.uk/document.php?o=227 (accessed 12 Mar 2015).

10. NICE. Lipid modification: cardiovascular risk assessment and the modification of blood lipids for the primary and secondary prevention of cardiovascular disease. CG67. London: National Institute of Health and Clinical Excellence, 2008.

11. Mihaylova B, Emberson J, Blackwell L, et al, Cholesterol Treatment Trialists (CTT) Collaborators. The effects of lowering LDL cholestero with statin therapy in people at low risk of vascular disease: meta-analysis of individual data from 27 randomised trials. Lancet 2012;380:581-90.

12. Taylor F, Huffman MD, Macedo AF, et al. Statins for the primary prevention of cardiovascular disease. Cochrane Database Syst Rev 2013;(1):CD004816.

13. Czernichow S, Zanchetti A, Turnbull F, et al. The effects of blood pressure reduction and of different blood pressure-lowering regimens on major cardiovascular events according to baseline blood pressure: meta-analysis of randomized trials. J Hypertens 2011:29:4-16.

14. Baigent C, Keech A, Kearney PM, et al. Efficacy and safety of cholesterol-lowering treatment: prospective meta-analysis of data from 90,056 participants in 14 randomised trials of statins. Lancet 2005;366:1267-78.

15. Jackson $\mathrm{R}$, Wells $\mathrm{S}$, Rodgers $\mathrm{A}$. Will screening individuals at high risk of cardiovascular events deliver large benefits? Yes. BMJ 2008;337:a1371.

16. Capewell S, Lloyd-Jones DM. Optimal cardiovascular prevention strategies for the 21st century. JAMA 2010;304:2057-8.

17. Ebrahim S, Taylor F, Ward K, et al. Multiple risk factor interventions for primary prevention of coronary heart disease. Cochrane Database Syst Rev 2011;(1):CD001561.

18. Berger JS, Jordan CO, Lloyd-Jones D, et al. Screening for cardiovascular risk in asymptomatic patients. J Am Coll Cardiol 2010;55:1169-77.

19. Mehta S, Wells S, Grey C, et al. Initiation and maintenance of cardiovascular medications following cardiovascular risk assessment in a large primary care cohort: PREDICT CVD-16. Eur J Prev Cardiol 2014:21:192-202. 
20. Ioannidis JP. More than a billion people taking statins? Potential implications of the new cardiovascular guidelines. JAMA 2014;311:463-4.

21. von Elm E, Altman DG, Egger $M$, et al. The Strengthening the Reporting of Observational Studies in Epidemiology (STROBE) statement: guidelines for reporting observational studies. J Clin Epidemiol 2008:61:344-9.

22. Health and Social Care Information Centre. NHS Health Check secondary use dataset, 2014. http://www.hscic.gov.uk/ nhshealthcheck (accessed 13 Mar 2014).

23. Office of National Statistics. Presentation of ethnic group data, 2015. http://www.ons.gov.uk/ons/guide-method/measuring-equality/ equality/ethnic-nat-identity-religion/ethnic-group/ presentation-of-ethnic-group-data.html (accessed 28 Aug 2015).

24. Townsend P, Phillimore P, Beattie A. Health and Deprivation: Inequality and the North. London: Croom Helm, 1988.

25. Robson J, Dostal I, Madurasinghe V, et al. The NHS Health Check programme: implementation in east London 2009-2011. BMJ Open 2015;5:e007578.

26. NICE. Lipid modification: cardiovascular risk assessment and the modification of blood lipids for the primary and secondary prevention of cardiovascular disease. CG181. London: National Institute for Health and Care Excellence, 2014.

27. Sheikh A, Nurmatov UB, Cresswell K, et al. Investigating the cost-effectiveness of health information technologies: a systematic review protocol. BMJ Open 2013;3:e003737.

28. Hippisley-Cox J, Coupland C, Vinogradova Y, et al. Predicting cardiovascular risk in England and Wales: prospective derivation and validation of QRISK2. BMJ 2008;336:1475-82.

29. Wells S, Furness S, Rafter N, et al. Integrated electronic decision support increases cardiovascular disease risk assessment four fold in routine primary care practice. Eur J Cardiovasc Prev Rehabil 2008;15:173-8.

30. Coffey C, Cooper AM, Brown T, et al. Vascular health checks in Salford. Manchester: University of Salford, 2014. http://usir. salford.ac.uk/35581/1/final_farsite_report.pdf (accessed 20 Aug 2015)

31. Chipchase L. An insight into the NHS health Check programme in Birmingham: NHS Health Checks national learning network, 2012. http://www.nhshealthcheck.nhs.uk/default.aspx?alD=45 (accessed 13 Mar 2014)

32. Hill S, Spink J, Cadilhac D, et al. Absolute risk representation in cardiovascular disease prevention: comprehension and preferences of health care consumers and general practitioners involved in a focus group study. BMC Public Health 2010;10:108.

33. Liew SM, Blacklock C, Hislop J, et al. Cardiovascular risk scores: qualitative study of how primary care practitioners understand and use them. Br J Gen Pract 2013;63:e401-7.

34. Krska J, du Plessis R, Chellaswamy H. Views and experiences of the NHS Health Check provided by general medical practices: cross-sectional survey in high-risk patients. $J$ Public Health (Oxf) 2015;37:210-17.

35. Artac M, Dalton AR, Majeed A, et al. Effectiveness of a national cardiovascular disease risk assessment program (NHS Health Check): results after one year. Prev Med 2013;57:129-34.

36. Smith S, Waterall J, Burden AC. An evaluation of the performance of the NHS Health Check programme in identifying people at high risk of developing type 2 diabetes. BMJ Open 2013;3:pii: e002219.

37. van Staa TP, Smeeth L, Ng ES, et al. The efficiency of cardiovascular risk assessment: Do the right patients get statin treatment? Heart 2013:99:7.

38. Prochazka AV, Lundahl K, Pearson W, et al. Support of evidence-based guidelines for the annual physical examination: a survey of primary care providers. Arch Intern Med 2005;165:1347-52.

39. Krogsboll LT, Jorgensen KJ, Gronhoj Larsen C, et al. General health checks in adults for reducing morbidity and mortality from disease: Cochrane systematic review and meta-analysis. BMJ 2012;345: e7191.

40. Krogsboll LT, Jørgensen KJ, Gøtzsche PC. Health checks. Letter to the editor. The Times 20/08/2013.

41. Krogsboll LT, Jorgensen KJ, Gotzsche PC. Universal health checks should be abandoned. BMJ 2013;347:f5227.

42. Shapiro S, Fink R, Rosenberg C. A program to measure the impact of multiphasic health testing on health differentials between poverty and nonpoverty groups. Med Care 1972;10:207-14.
43. Thorner RM, Djordjevic D, Vuckmanovic C, et al. A study to evaluate the effectiveness of multiphasic screening in Yugoslavia. Prev Med 1973;2:295-301.

44. South-East London Screening Study Group. A controlled trial of multiphasic screening in middle-age: results of the South-East London Screening Study. The South-East London Screening Study Group. Int J Epidemiol 1977;6:357-63.

45. Bennett $A E$, Fraser IG. Impact of a screening programme in general practice: a randomized controlled trial. Int J Epidemiol 1972;1:55-60.

46. Tibblin G, Welin L, Larsson B, et al. The influence of repeated health examinations on mortality in a prospective cohort study, with a comment on the autopsy frequency. The study of men born in 1913. Scand J Soc Med 1982;10:27-32.

47. Lannerstad $\mathrm{O}$, Sternby $\mathrm{NH}$, Isacsson SO, et al. Effects of a health screening on mortality and causes of death in middle-aged men. A prospective study from 1970 to 1974 of mean in Malmo, born 1914 . Scand J Soc Med 1977;5:137-40.

48. Olsen DM, Kane RL, Proctor PH. A controlled trial of multiphasic screening. N Engl J Med 1976;294:925-30.

49. Wilhelmsen L, Berglund G, Elmfeldt D, et al. The multifactor primary prevention trial in Goteborg, Sweden. Eur Heart J 1986;7:279-88.

50. Friedman GD, Collen MF, Fireman BH. Multiphasic health checkup evaluation: a 16-year follow-up. J Chronic Dis 1986;39:453-63.

51. World Health Organization European Collaborative Group. WHO European collaborative trial in the multifactorial prevention of coronary heart disease. WHO, 1989.

52. No authors listed]. Effectiveness of health checks conducted by nurses in primary care: final results of the OXCHECK study. Imperial Cancer Research Fund OXCHECK Study Group. BMJ 1995;310:1099-104.

53. Scandinavian Simvastatin Survival Study Group. Randomised trial of cholesterol lowering in 4444 patients with coronary heart disease: the Scandinavian Simvastatin Survival Study (4S). Lancet 1994:344:1383-9.

54. Theobald H, Bygren LO, Carstensen $\mathrm{J}$, et al. Effects of an assessment of needs for medical and social services on long-term mortality: a randomized controlled study. Int $J$ Epidemiol 1998;27:194-8.

55. Jorgensen $\mathrm{T}$, Borch-Johnsen $\mathrm{K}$, Thomsen TF, et al. A randomized non-pharmacological intervention study for prevention of ischaemic heart disease: baseline results Inter99. Eur J Cardiovasc Prev Rehabil 2003;10:377-86.

56. Thomsen JL, Parner ET, Karlsmose B, et al. Effect of preventive health screening on long-term primary health care utilization. A randomized controlled trial. Fam Pract 2005;22:242-8.

57. Jorgensen T, Jacobsen RK, Toft U, et al. Effect of screening and lifestyle counselling on incidence of ischaemic heart disease in general population: Inter99 randomised trial. BMJ 2014;348: g3617.

58. Daily Mail. Why statins might be pointless and even bad for you 2008. http://www.dailymail.co.uk/health/article-1340299/ Why-taking-statins-pointless--bad-you.html

59. Godlee F. Statins and the BMJ. BMJ 2014:349:95038.

60. Collins R. Doctors fears over statins may cost lives. The Guardian 21/3/2014.

61. Appleby J. Is general practice in trouble? BMJ 2014:349:96814

62. Majeed A, Rawaf S, De Maeseneer J. Primary care in England: coping with financial austerity. Br J Gen Pract 2012;62:625-6.

63. National Audit Office. Delivering efficiency savings in the NHS 2011. http://www.nao.org.uk/wp-content/uploads/2011/12/NAO briefing_Delivering_efficiency_savings_NHS.pdf (accessed 12 Mar 2015).

64. NHS England. NHS Health Checks Data, 2011. http://www.england. nhs.uk/statistics/statistical-work-areas/integrated-performancemeasures-monitoring/nhs-health-checks-data (accessed 12 Mar 2015).

65. Research Works Limited. Understanding the implementation of NHS Health Checks: Research Report: Public Health England, 2013. http://www.healthcheck.nhs.uk/document.php?o=351 (accessed 20 Feb 2014)

66. Public Health England. NHS Health Check implementation plan review and action plan, 2013. https://www.gov.uk/government/ uploads/system/uploads/attachment_data/file/224805/NHS_Health_ Check_implementation_review_and_action_plan.pdf (accessed 13 Mar 2015). 